\section{Aftercare for Patients with Transplanted Organs}

by Dr. med. Harald Schrem, Dr. med. Hannelore Barg-Hock, Prof. Dr. med. Christian P. Strassburg, Prof. Dr. med. Anke Schwarz, Prof. Dr. med. Jürgen Klempnauer in volume 9/2009

\section{How Up to Date Was This Information?}

I have several criticisms relating to the published box. No mention is made of its source.

In the United States, West Nile virus occurs to an epidemiologically relevant degree in birds and humans; transmission to humans in Germany has not occurred thus far, according to all reports that are currently available. Further investigations in the Robert KochInstitute have not provided any indication of the prevalence of this flavivirus in humans in Germany either.

LCMV refers to the lymphochoriomeningitis virus, not the lymphocytic choriomeningitis virus, This arenavirus occurs in rodents in the US, especially in mice. In Germany, no infection has thus far occurred, even in children.

SARS is the "severe acute respiratory syndrome" coronavirus, which was epidemiologically highly relevant in 2002 and 2003. A less pathogenic similar coronavirus caused a second small epidemic in China in 2004; since then, this zoonotic coronavirus has remained irrelevant for central Europe and the US.

Pneumocystis is clinically important after transplantation. However, since 2004/05, this fungus, which occurs in human beings, has been renamed Pneumocystis jirovecii and not Pneumocystis carinii.

An article that was published in 2009 should have included current terminology and meanings..

DOI: 10.3238/arztebl.2010.0037a

\section{REFERENCES}

1. Schrem H, Barg-Hock H, Strassburg CP, Schwarz A, Klempnauer J: Aftercare for patients with transplanted organs. Dtsch Arztebl Int 2009; 106(9): 148-55

Prof. Dr. med. Dr. rer. nat. habil. Lutz Gürtler Institut für Medizinische Virologie Universität Frankfurt

Paul Ehrlich Str. 40, 60596 Frankfurt, Germany

lutzg.guertler@vodafone.de

\section{Recommended Fluid Intake Should Be Tailored to the Individual}

We wish to comment on two critical issues in this otherwise excellent article.

- Complex bone disease after renal transplantation (NTX) is not the same as steroid induced osteoporosis. Bisphosphonates after NTX should not be used in analogy to the guidelines from the umbrella organization for osteology (Dachverband Osteologie, DVO e.V.) as a general rule (use during steroid treatment $>3$ months or in patients with an osteoporotic fracture $+\mathrm{T}$ score $<-1.5$ ), because:
- Although bone density after NTX increases when bisphosphonates are given, this is not a good predictor for fractures after NTX, and a drop in the incidence of fractures has not been shown (1).

- Adynamic bone disease is the most common bone pathology in dialysis patients. It often persists after NTX. Using antiresorptive drugs in such situations seems a questionable approach (long term complications?) (2).

- The optimum dosage and duration of bisphosphonate use, and the best administration method, remain unclear.

Current nephrology guidelines (KDOQI, Kidney Disease Outcome Quality; KDIGO, Kidney Disease Improving Global Outcomes; EBPG, European Best Practise Guidelines) do not provide a clear recommendation for the use of bisphosphonates after NTX. In an NTX patient with unsuppressed bone metabolism who is at a high risk of fractures, bisphosphonates certainly feature among the individualized treatment options. In addition to bone densitometry, however, clinical risk factors should be included in any assessment of fracture risk. The cornerstones of therapy primarily include adjusting immunosuppression, optimizing renal osteodystrophy therapy, physical activity, and preventing falls.

- A global recommendation for fluid intake of more than 2 liters/day should be made on an individual basis only. It is indicated in NTX patients with recurrent urinary tract infections, for example. On the other hand, reports are increasing that in patients with impaired renal function, drinking more than $2 \mathrm{~L} / \mathrm{d}$ accelerates the further loss of kidney function (3). Although this has not been the subject of formal studies in the context of NTX, we think that a daily intake of $1.5-2 \mathrm{~L}$ is sufficient in most renal transplant patients.

DOI: 10.3238/arztebl.2010.0037b

\section{REFERENCES}

1. Conley E, Muth B, Samaniego M, et al.: Bisphosphonates and bone fractures in long-term kidney transplant recipients. Transplantation 2008; 86: 231-7.

2. Coco M, Glicklich D, Faugere MC, et al.: Prevention of bone loss in renal transplant recipients: a prospective, randomized trial of intravenous pamidronate. J Am Soc Nephrol 2003; 14: 2669-76.

3. Hebert LA, Greene T, Levey A, Falkenhain ME, Klahr S: High urine volume and low urine osmolality are risk factors for faster progression of renal disease. Am J Kidney Dis 2003; 41: 962-71.

4. Schrem H, Barg-Hock H, Strassburg CP, Schwarz A, Klempnauer J Aftercare for patients with transplanted organs. Dtsch Arztebl Int 2009; 106(9): 148-55.

Prof. Dr. med. Jürgen Floege

Dr. med. Vincent Brandenburg

Medizinische Klinik II

Klinik für Nephrologie, UK Aachen

Paulwelstr. 30

52074 Aachen, Germany

Vincent.Brandenburg@post.rwth-aachen.de 